\title{
Arguments from Fairness and Misplaced Priorities in Political Argumentation
}

\author{
Douglas N. Walton ${ }^{1} \&$ Hans V. Hansen ${ }^{1}$ \\ ${ }^{1}$ Centre for Research in Reasoning, Argumentation and Rhetoric (CRRAR), University of Windsor, Windsor, \\ Ontario, Canada \\ Correspondence: Douglas N. Walton, CRRAR, 312a Essex Hall, University of Windsor, Windsor, Ontario N9B \\ 3P4 Canada. Tel: 1-519-253-3000 Ext. 2362. E-mail: dwalton@uwindsor.ca. Hans V. Hansen, Department of \\ Philosophy, University of Windsor, Chrysler Hall North, Room 2169, 401 Sunset Avenue, Windsor, Ontario N9B \\ 3P4. Tel: 1-519-253-3000 ext. 2342. E-mail: hhansen@uwindsor.ca.
}

\author{
Received: April 26, 2013 Accepted: May 13, 2013 Online Published: August 30, 2013 \\ doi:10.5539/jpl.v6n3p78 URL: http://dx.doi.org/10.5539/jpl.v6n3p78
}

\begin{abstract}
Argumentation schemes are formal structures that are used to represent types of arguments that are prominent in natural language discourse. Recent research in argumentation studies has identified and investigated many of these schemes. The two types of arguments studied in this paper, found to be used during a pilot study of kinds of arguments used by the candidates in a recent Ontario provincial election, have not so far been formalized as schemes. We call them argument from fairness and argument from misplaced priorities. We formulate schemes for them, and analyze several examples of them from our corpus by means of constructing argument diagrams that fit the argument into the scheme.
\end{abstract}

Keywords: argumentation schemes, political rhetoric, argument mining, argument mapping

\section{Introduction}

Argumentation schemes are forms of argument that capture stereotypical patterns of reasoning used by an agent, whether human or artificial, to an inferred conclusion based on a set of premises (Walton, Reed \& Macagno, 2008). The kinds of arguments that are the focus of study in this paper are defeasible in nature. Argumentation schemes of this defeasible kind are especially useful to represent structures of human reasoning that cannot be analyzed as deductively (or even inductively) valid (Kienpointner, 1987). They can be equated with heuristics of the kind studied in cognitive science. Heuristics are "fast and frugal" devices of reasoning that are useful in arriving at a decision to proceed tentatively on a defeasible basis under constraints of time pressure and lack of complete knowledge (Gigerenzer et al., 1999).

The purpose of this paper is to present two new argumentation schemes not in the list of Walton, Macagno and Reed (2008) that were found in a research project on argumentation in media reporting on a recent election campaign in Canada. One problem was that several interesting cases of arguments found in the material did not fit any known schemes. In the project, we put forward the hypothesis that two new argumentation schemes had to be constructed in order to model these examples. The structure of one of the schemes, we found later, was well understood by Perelman (1982), as had even been recognized as a common form of argument by Aristotle. Our contribution was to model it in a format suitable for recent argumentation research. The scheme for argument from fairness is analyzed as a species of value-based reasoning (Bench-Capon, 2003) while the scheme for argument from misplaced priorities is analyzed as a species of priority-based reasoning (Prakken \& Sartor, 1997).

Mochales Palau and Moens (2009) applied argumentation schemes to a corpus of texts of judgments of the European Court of Human Rights. The cases were annotated by three annotators under supervision of a legal expert to analyze legal argumentative texts. The aim of the project was to build a system for automatic detection and classification of arguments in legal cases. This technique of automatically detecting particular types of arguments in text using argumentation schemes is called argument mining. This kind of work in computational linguistics is very encouraging, but so far, we know of no empirical research that works with natural language texts of discourse outside the legal domain that attempts to identify particular arguments found in a natural language corpus by using argumentation schemes. As far as we know, ours is the first systematic attempt to use schemes of 
the types now widely used in artificial intelligence models of natural language argumentation to identify types of arguments in media reports of political argumentation used in an election setting.

Section 1 introduces the reader to our pilot study on kinds of arguments used in the recent provincial election campaign in Ontario, and to argumentation schemes commonly used in political discourse. This section also introduces the reader to the Carneades Argumentation System, a software system that has an argument mapping tool that can be used to build a visual representation of an argument. Such an argument diagram can display the structure of the argument, the premises and conclusions in it, and can display parts of the argument where an argumentation scheme has been applied. The argument diagrams provide a way of presenting the essential structure of each argument in a way that is easy for anyone to grasp.

Section 2 introduces the central argumentation scheme that is the focus of the paper, argument from fairness and shows how this scheme has already been recognized by Aristotle and Perelman. To give the reader a clear idea of the importance of argument from fairness, an example of its use in judicial decision-making is given. Sections 3 and 4 present and analyze the first two examples of argument from fairness from the corpus of arguments collected in the study on the Canadian election. Section 5 presents another type of argument that can be confused with argument from fairness, called argument from misplaced priorities. Section 6 gives an example of a borderline argument that readers might possibly be inclined to interpret one way or the other, and shows how to disambiguate the two schemes. Section 7 provides some conclusions to the paper.

As part of a current project studying political argumentation we conducted a pilot study of what kinds of arguments candidates in the recent provincial election in Ontario used. During the election period, September and October, 2011, our team collected about 250 arguments found in four leading newspapers. The aim of the study was to find out which kinds of arguments are most commonly used in the discourse of political election campaigns, or at least to take some beginning steps in designing a comprehensive study that would explore this question. Our pilot study was a way of testing the completeness of a given list of schemes and eventually coming up with a more comprehensive list of schemes that would be adequate for studying political argumentation. A secondary question we considered was whether some kinds of arguments were used more frequently than others in general and by some political parties in particular. The findings can be found in (Hansen \& Walton, 2013).

Our method was to try to fit all the arguments we found into schemes by using a list of schemes that seemed fairly comprehensive and applicable from (Walton, 2006). This set of schemes is based on many analyses of examples of arguments collected from logic textbooks as well as examples of real arguments from everyday discourse, many from media reports of political argumentation. The list consisted of fourteen schemes plus a category of 'none of the above'.

1. Argument from position to know; 2. argument from expert opinion; 3. argument from popular opinion; 4. argument from commitment; 5 . argument from ignorance; 6 . circumstantial ad hominem argument; 7 . abusive ad hominem argument; 8. argument from correlation to cause; 9. argument from positive consequences; 10. argument from negative consequences; 11. slippery slope argument; 12. argument from analogy; 13. argument from sign; 14. argument from (verbal) classification; 15. none of the above.

After the collecting stage of the study was finished we turned to the analysis stage. Independently, we and four students tried to classify each argument collected as fitting one or another of these schemes. After group discussion we found that over one-third (37.1\%) of the arguments collected did not fit any of the fourteen schemes on our initial list. This led us to supplement the list with some other recognized argument schemes (e.g., the practical reasoning scheme). Of the "no-fits" that still remained unclassified after the addition of other schemes, we noticed that some of them could be grouped together as being of the same argument kind. It was this discovery that has led us to propose the two new schemes that are the object of study in this paper. With our new expanded list of schemes we were able to classify all but five per cent of the arguments collected - an improvement of more than $30 \%$.

One of the kinds of argument that recurred with significant frequency concerns the justice or injustice of policies or actions. A form of argument of this kind had been recognized by Perelman and Olbrechts-Tyteca (1969) and more fully by Perelman (1980), and we discuss this version of it below and go on to introduce a scheme for the argument from fairness (or justice), and its variant the argument from injustice. A related but distinct kind of argument we also discuss is the argument from misplaced priorities and its proposed scheme. As the standard formalism used to represent and discuss the argumentation structure of each of the examples analyzed in the paper we will use the Carneades Argumentation System.

The Carneades Argumentation System is an Open Source software project that provides tools for argument mapping and visualization, argument evaluation, proof standards that determine burden of proof, and argument 
construction from precedent cases. The system has been implemented as an open source software program that is available at no cost on the Internet (http://carneades.github.com/). Anyone can draw argument diagrams showing inferential relationships among premises and conclusions of arguments with the graphical user interface. An argument is defined as a set of premises, $P$, a set of exceptions, $E$, and a conclusion $c$. An argument can be either pro or con a statement, or pro or con another argument. Arguments are combined by recursive definitions of applicability of an argument and acceptability of its conclusion. There are three kinds of counterarguments in the Carneades system. One is a premise attack argument. Another is an attack against the conclusion of the second argument. The third is the undercutter, which attacks the argument itself rather than the premise or the conclusion. A rebuttal is a counterargument that is stronger than the argument attacked.

Carneades supports and uses argumentation schemes. Argumentation schemes can be applied to an argument that has been put forward in a dialogue to determine whether requirements of the scheme have been met. One of the capabilities of the scheme is to identify appropriate critical questions that can be asked by an opponent. In the Carneades system, critical questions matching a scheme are modeled as kinds of premises of the scheme: ordinary premises, assumptions or exceptions. Ordinary premises are ones explicitly stated as premises in the argumentation scheme. Assumptions are premises that are assumed to hold, just like the ordinary premises. As soon as they are questioned by the opponent's asking an appropriate critical question, they default until the proponent offers backup evidence to support the premise. The burden of proof is on the proponent to reply, or he must retract the premise. Exceptions are premises that are assumed not to hold unless evidence is given by the critical questioner to back them up. Here the burden of proof is on the other party. Asking a critical question that is classified as an exception does not defeat the argument unless the opponent gives backup evidence to support the question.

An example of how a typical argument is visualized as an argument map in Carneades is shown in figure 1.

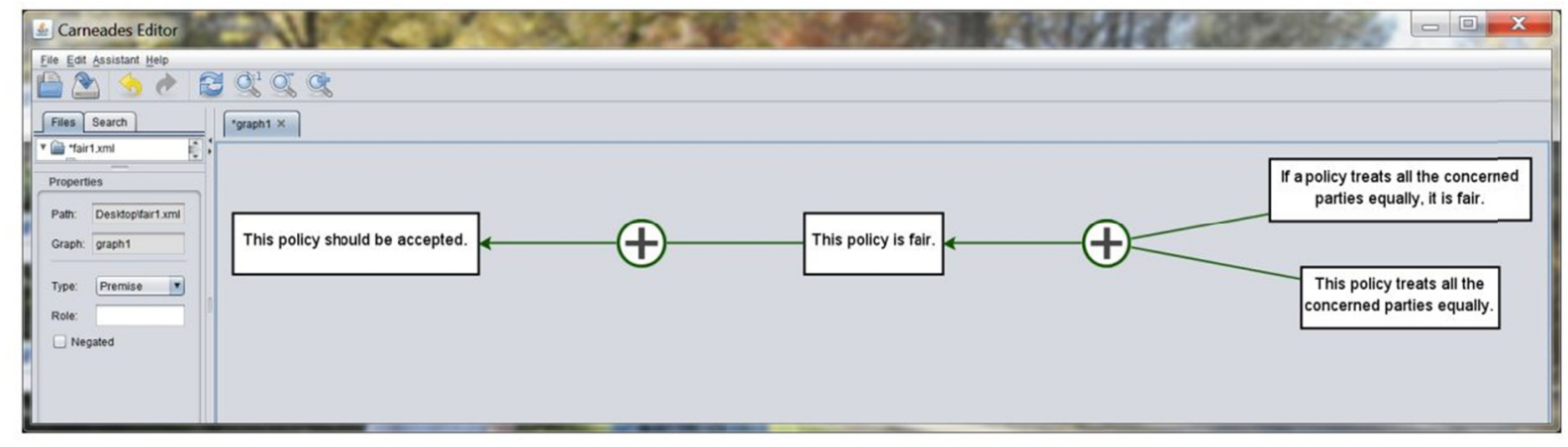

Figure 1. How a carneades argument map looks on the screen

The part on the left is the menu where the user inputs the information needed to construct, analyze and evaluate the argument. The argument diagram that has been constructed as an example is shown on the right. The conclusion is the statement that this policy should be accepted. Supporting it is a pro-argument, indicated by the plus sign in the argument node, which has a single premise, namely the statement that this policy is fair. At the next step this premise is itself supported as a conclusion by the two other premises shown to the right of it.

\section{Scheme for Argument from Fairness}

Perelman and Olbrechts-Tyteca $(1969,218)$ wrote, "The rule of justice requires giving identical treatment to beings or situations of the same kind". Pereleman (1982), however, made the insightful philosophical remark that two different things can never be identified as identical unless they are the same thing. Therefore "in practice, the problem is to know in which case it is rational or just to treat in the same way two beings or situations which differ but which can be likened to each other"(Perelman, 1982, 65). Perelman (1980, 11) offers the following definition of what he calls formal or abstract justice: it is "a principle of action in accordance with which beings of one and the same essential category must be treated the same way". What is an essential category? He explains what this means by telling us that despite their individual disagreements, everyone is agreed that to be just is to give the same treatment to those who possess a particular characteristic that groups people together into a class or category defined by the fact that its members possess the characteristic (Perelman, 1980, 11). So for example, if it is contended that fairness requires that equal treatment be given to all persons who have the same needs, the essential 
characteristic will be that of having the same needs. Our treatment of examples of arguments from fairness will bring out the wisdom of Perelman's insight on how this notion of fairness (justice) can be applied to particular cases.

Accordingly, when it comes to the legal problem of elaborating rules of conduct determining obligations that are to be imposed on individuals who can be classified together in a certain way, the generally accepted principle of equality is that everyone who possesses characteristics that are stipulated by the law will be treated the same way (Perelman, 1982, 66). It is this general rule he calls the rule of justice, and it gives rise to what he calls the argument of reciprocity, which says that "if two terms are symmetrical and can be inverted without difficulty, we can claim that is it is necessary to equate the terms and that there is reason to apply to them the rule of justice which demands equal treatment" (Perelman, 1982, 67).

The problem with using the term 'equally' in the scheme is that equality is a highly contested concept in social and political philosophy (Gosepath, 2011). Yet we want to avoid building any particular political philosophy into the argumentation scheme from fairness. How can we reckon with the possibility that, as a matter of empirical fact, arguments from fairness in political discourse inevitably embody particular political or philosophical views, for the reason that that is how politicians argue? So why would any argumentation scheme for argument from fairness be politically neutral? Perelman $(1980,10)$ has a nice answer to this question. He states that he is looking for a formula of justice common to many different political conceptions of it, an underlying concept that can constitute a definition of what he calls "formal" or "abstract" justice. The common idea that we all agree on is formulated by Perelman in the following simple proposition: to be just is to be treated in an equal fashion. But then, he goes on, problems arise. Does everyone have to be treated in the same way, or do we have to draw a distinction? Every person advocates a different system in response to these questions, and the problem is that no system secures universal agreement. Some say that merits have to be taken into account, while others say that needs must be taken into account. Perelman $(1980,10)$ contends, nevertheless, that despite these political differences all are agreed that to be just is to give the same treatment to those who are equal with regard to one particular characteristic. We will avoid building any particular political philosophy or viewpoint into the argumentation scheme for argument from fairness by following Perelman's way of defining fairness as an abstract or formal notion.

Following this approach any two things or treatments of persons being compared on the basis of equality need not be identical in every respect. They must be different in certain respects in order to be held to be equal in other respects. It is useful to see that variation of equality with 'respects' was also emphasized by Aristotle's treatment of justice. Aristotle distinguished between two kinds of equality, numerical and proportional. The distribution of goods or treatment of others is equal numerically when it treats them identically, for example by giving each the same quantity of goods or honor. The treatment of others as proportional refers to persons being treated as equal or unequal in certain respects (Nicomachean Ethics, 1131b17-1131b18). So Aristotle's notion of justice can be classified as one of proportional equality. It is this Aristotelian notion of proportional equality that can best be used in the scheme for argument from fairness. It fits with Perelman's approach in this regard.

According to Aristotle's theory (Nicomachean Ethics, 1131a10-113129), the notion of justice is based on a prior notion of fairness, which is in turn based on a prior notion of equality, and equality is based on the notion of proportionality. Aristotle even explains this notion of proportionality using a geometric diagram (Nicomachean Ethics, 1132b9-1131b11), but it also relates to his theory of the golden mean in ethics, a theory that views excellence and qualities of character and actions as meeting an intermediate between two extremes. The following quotation (Nicomachean Ethics, 1131a10-113129) gives the reader an idea of how his theory of justice and injustice work in outline.

We have shown that both the unjust man and the unjust act are unfair or unequal; now it is clear that there is also an intermediate between the two unequals involved in either case. And this is the equal; for in any kind of action in which there is a more and a less there is also what is equal. If, then, the unjust is unequal, just is equal, as all men suppose it to be, even apart from argument. And since the equal is intermediate, the just will be an intermediate. Now equality implies at least two things. The just, then, must be both intermediate and equal and relative (i.e. for certain persons). And qua intermediate it must be between certain things which are respectively greater and less); qua equal, it involves two things; qua just, it is for certain people. The just, therefore, involves at least four terms; for the persons for whom it is in fact just are two, and the things in which it is manifested, the objects distributed, are two. And the same equality will exist between the persons and between the things concerned; for as the latter-the things concerned-are related, so are the former; if they are not equal, they will not have what is equal, but this is the origin of quarrels and complaints-when either equals have and are awarded unequal shares, or unequals equal shares. Further, this is plain from the fact that awards should be 'according to 
merit'; for all men agree that what is just in distribution must be according to merit in some sense, though they do not all specify the same sort of merit, but democrats identify it with the status of freeman, supporters of oligarchy with wealth (or with noble birth), and supporters of aristocracy with excellence.

These remarks provide a background for a way of representing arguments based on premises that make claims about fairness and unfairness. Here there is no space for us to try to relate this Aristotelian approach to other philosophies of justice. Nor do we need to attempt to do this. All we need is enough of the structure of the Aristotelian approach to show how arguments from fairness and unfairness relate to notions of justice and injustice that are based on some prior notions of equality and inequality that can vary in the way indicated by Perelman when applying the abstract notion to individual instances of arguments. We are not necessarily endorsing the way Aristotle defines equality and inequality using his geometrical theory of the mean.

We propose a scheme of the following sort. $\varphi$ is an action, or in some instances a general policy for action. $\alpha$ and $\beta$ are agents or groups of agents. $\psi$ is a different policy or action that is being considered or has been implemented as an alternative to $\varphi$. We call this scheme version 1 of Argument from Fairness.

Major Premise: If $\varphi$ treats $\alpha$ and $\beta$ equally then $\varphi$ is fair (just).

Minor Premise: Action (policy) $\varphi$ treats $\alpha$ and $\beta$ equally.

Conclusion: $\varphi$ should be carried out.

This first version appears to have a missing premise, and in section 3 it is discussed how to complete it. There are many counter-arguments that could be used to reply to the argument from fairness, but to help search for some points on which such an argument can generally be questioned, there are five basic critical questions matching this scheme.

$\mathrm{CQ}_{1}$ : Are agents $\alpha$ and $\beta$ of the same kind?

$\mathrm{CQ}_{2}$ : In what respects are $\alpha$ and $\beta$ equal?

$\mathrm{CQ}_{3}$ : In what respects are $\alpha$ and $\beta$ different?

$\mathrm{CQ}_{4}$ : Are there special circumstances such that $\alpha$ and $\beta$ should not be treated equally?

$\mathrm{CQ}_{5}$ : Are there reasons supporting $\varphi$ ?

There are four general requirements a given argument in the text of discourse needs to meet in order to fit this scheme. The first is that there is some action or policy being considered or discussed. The second is that there are two sides to the discussion, meaning that there is a proponent who advocates the action or policy and an opponent who is against it, or doubtful about it. The third is that the proponent is putting the argument forward in order to support the action or policy. The fourth requirement is that the argument is meant to overcome reservations that might be held about the action or policy at issue. Thus if we have a case where somebody is calling some action or policy fair, that is not enough in itself to say that we have an instance of argument from fairness. It may be just a statement that the action or policy is fair. In order for there to be an argument from fairness to have been advanced, the fairness that is alleged has to be put forward as a reason for going ahead with the action, or adopting the policy that is being considered.

It is important to note that there is also a negative version of the same general form of argument. It could be called the argument from unfairness. It has the same structure as the argument from fairness, but it is an argument against the action or proposal being considered.

Major Premise: If $\varphi$ treats $\alpha$ and $\beta$ unequally then $\varphi$ is unfair (unjust).

Minor Premise: Action (policy) $\varphi$ treats $\alpha$ and $\beta$ unequally.

Conclusion: $\varphi$ should not be carried out.

The critical questions for argument from unfairness are comparable to those for argument from fairness, except that it needs to be taken into account that the argument from unfairness is the negative version of the argument from fairness.

As above, there are four requirements for some discourse in a text to properly be classified as an instance of the argument from unfairness. The first is that there is some action or policy that is being considered or discussed. The second is that there are two sides to the discussion, meaning that there is a proponent and an opponent. The third requirement is that the proponent has advocated going ahead to carry out this action or implement this policy. The fourth requirement is that the opponent is attempting to argue against the proponent's argument by using this 
particular form of argument. This means that if $\varphi$ is unfair to somebody who should be considered, that is a reason for not carrying out $\varphi$.

Arguments from fairness and unfairness are very important in legal reasoning in judicial decision-making. In the case of Popov v Hayashi (Popov v. Hayashi 2002 WL 31833731 (Cal. Superior, Dec. 18, 2002) the $73^{\text {rd }}$ homerun ball hit by Barry Bonds that season went into the stands, and into the upper portion of the glove of fan Alex Popov. Popov was just at that instant thrown to the ground by a mob of fans trying to obtain the ball, potentially worth millions of dollars. The ball ended up on the ground, but just then another fan, Patrick Hayashi, picked it up and put it in his pocket. Hayashi was not part of the mob that had knocked Popov down. Which of the two fans had the right to ownership of the ball? Judge McCarthy reasoned that an award of the ball to Popov would be premised on the assumption that he would have caught the ball if the crowd had not knocked him down. But this assumption was not supported by the facts, and so Judge McCarthy reasoned that it would be unfair to Hayashi to award the ball to Popov. On the other hand, the assumption that Popov would have dropped the ball was not supported by the facts either. So Judge McCarthy reasoned that any award to one party would be unfair to the other $(2002,10)$. This posed a dilemma on how to arrive at a decision based on the evidence as well as the lack of evidence. To resolve the dilemma, Judge McCarthy proposed that the ball should be sold and the proceeds divided equally between the two parties. The reasoning supporting this conclusion is an instance of argument from fairness, because the decision to split the proceeds was based on the premise that an award of the ball to either side would have been unfair. The notation $\mathrm{f}$ used in figure 2 represents the scheme for argument from fairness and the notation $\mathrm{u}$ represents the scheme for argument from unfairness. The notation + represents a pro argument and - represents a con argument.

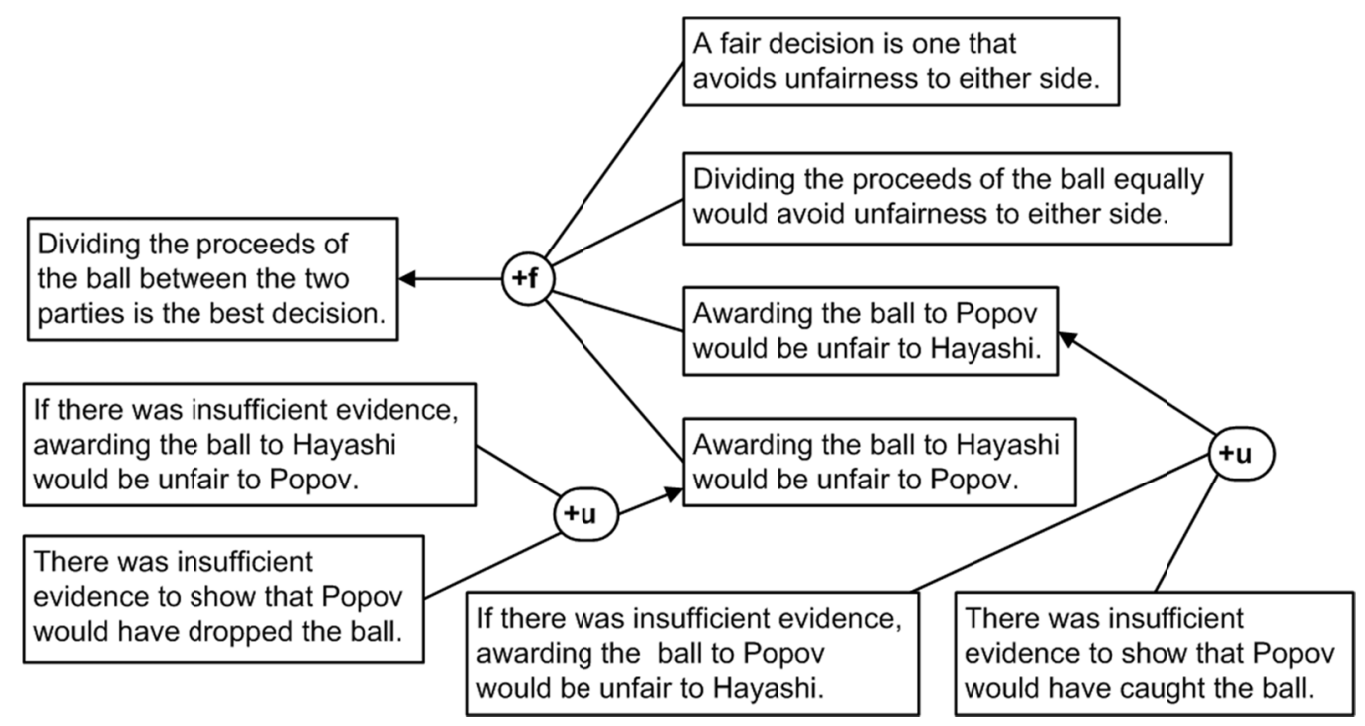

Figure 2. Argument map of Judge McCarthy's reasoning in Popov v. Hayashi

Recent research in cognitive science suggests that negative reactions to being treated unfairly are not unique to humans. Experiments with female capuchin monkeys have demonstrated the existence of inequity aversion in animals, the tendency to reject or avoid situations where there is perceived unfairness. In one experiment, called 'Monkeys Reject Unequal Pay' (Brosnan and de Waal, 2003), pairs of monkeys were given an equal reward for the same task, while other pairs were given unequal rewards for the same task. The monkeys given unequal rewards were much less likely to complete a trade with the experimenter, and when the inequality of rewards was even greater, the unwillingness to complete a trade intensified. The reactions of the monkeys to an unfair exchange ranged from passive rejections of refusing to take the rewards, to active rejections of throwing the reward, to refusal to conduct future exchanges with human researchers. In some instances monkeys even hurled their food rewards at researchers.

We are drawing attention to this research in cognitive science not to suggest the hypothesis that monkeys use the scheme for argument from unfairness, but to remark that this form of argumentation stems from a powerful reaction that is emotionally compelling. One can easily observe this reaction when small children say with a good deal of emphasis, "That's not fair!" 
According to dual process theories in cognitive science, there are two systems of reasoning. The one that has been emphasized almost exclusively in traditional logic is a rule-based system that is conscious, calculative and slow. Heuristics are said to be "fast and frugal" in use of resources (Gigerenzer et al., 1999). The other system is automatic and fast. It instinctively jumps to a conclusion that is sometimes wrong, but that can nevertheless in many instances be justified as a tentative hypothesis under conditions of uncertainty and lack of knowledge, and even inconsistency in some instances. The fast system uses heuristics or rules of thumb that often work very well (Gigerenzer et al., 1999). They are extremely useful in arriving at a decision to proceed tentatively on a defeasible basis under constraints of time pressure and lack of complete knowledge. Trial and error, for example, is sometimes a better way of solving the problem than taking the time and economic resources needed to collect data required to arrive at a more definitive solution.

Defeasible argumentation schemes tend to fall into the category of heuristics. Their defeasible nature implies not only that they sometimes fail when applied in specific instances as arguments, but even that in some cases they can be used as instruments of deception to try to get the best of a speech partner unfairly (Walton, 2010). Argument from expert opinion is a case in point. In many instances, we need to rely on arguments from expert opinion, but this type of argument can also be used to appeal to authority in a dogmatic way to try to intimidate in order to suppress critical questioning of a dubious claim. What we are suggesting is that arguments from fairness are emotionally compelling because they represent a heuristic that we learn naturally and early in our development. As such, they have two sides.

In this paper, we are at the very beginning of the study of arguments from fairness. Our purpose is not to evaluate the examples we now proceed to study as being weak or strong, reasonable or fallacious. We are simply trying to find a means to identify them as distinctive types of arguments used in particular cases by studying some examples.

\section{First Example of Argument from Fairness}

This example appeared in the Globe and Mail on 30/09/2011 with the title 'Prison Guard Union Not Endorsing Ontario PC Chain-gang Plan'. Tim Hudak, the Progressive Conservative leader in the Ontario election, told reporters that he believes that correctional officers are in favor of a work program which would require criminals to perform manual labor for up to forty hours a week in exchange for some compensation. His opponents derided the plan, calling it a chain gang initiative. Hudak said at a press conference that we are just asking the criminals to do what every other hard-working Ontarian does, an honest day's work instead of spending the day working out to become better criminals.

In this case, three arguments were given in support of his work program proposal. The first is that correctional officers are in favor of the work program. The second is an argument from fairness. The argument is made that criminals should be treated in the same way as other citizens with respect to having to put in an honest day's work. The third argument is that it is better for criminals to spend the day working than for them to spend the day "working out to become better criminals". There has also been an opposed argument put forward by opponents of the plan who called it "a chain gang initiative". Since this expression sounds highly negative, it is part of an argument against the work program proposal.

This example has been analyzed using the argument diagrams shown in figure 3 to see how the argument from fairness, as we have configured it so far, fits into the sequence of argumentation. Argument from fairness is indicated by an $f$ in a node.

The ultimate conclusion is the statement that the work program should be carried out, shown in the text box at left in the middle. Each argument that relates to this conclusion is shown by a node containing a plus or a minus sign. An argument that has a plus sign in its node is a pro argument, an argument that supports the conclusion. An argument that has a minus sign in its node is a con argument, an argument that attacks (attempts to refute) the conclusion. For convenience in order to discuss the example, each argument has been labeled with the number, A1, $\mathrm{A} 2$, and so forth.

As soon as we analyze the argument in this way, a problem about the argumentation scheme for argument from fairness is revealed. This problem is for us to figure out a way of determining which part or parts of the chain argumentation as presented in figure 3 should be taken to fit the scheme for argument from fairness as we have configured it above. Two candidates suggest themselves. One is argument A4, while the other is argument A2. A third possibility is that it is the combination of A4 and A2 that best represents the structure of the argument from fairness. If this third possibility is the best approach, we need to reconfigure the scheme for argument from fairness to make it more complex. 


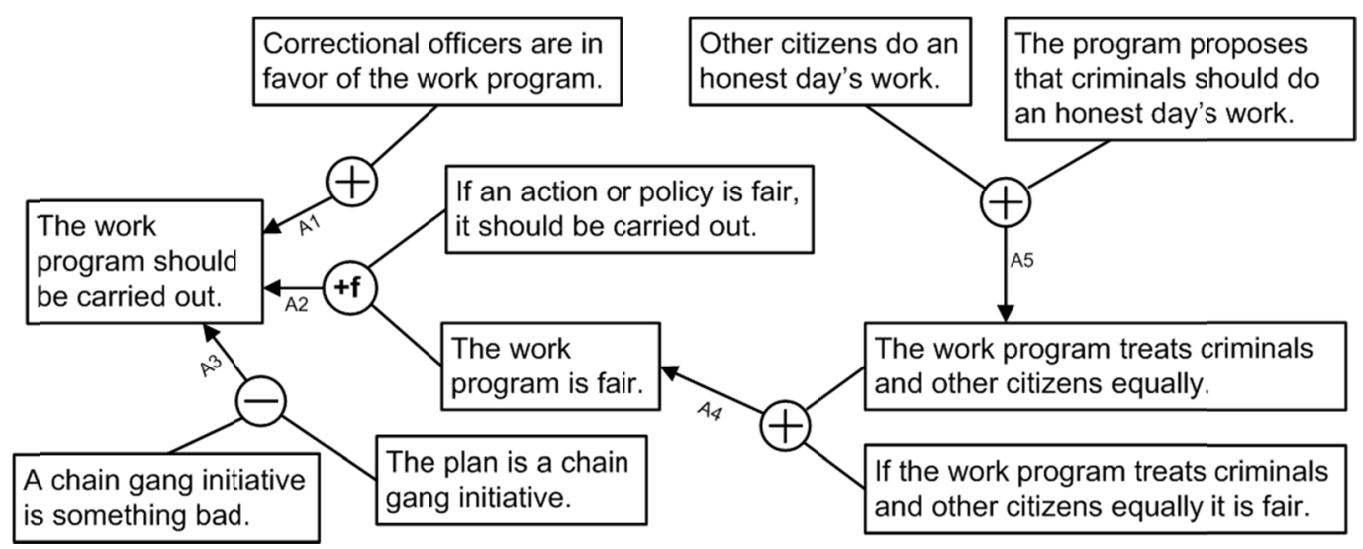

Figure 3. Argument diagram of the work program example

The third possibility requires breaking down the argument from fairness into two sub-arguments.

First Argument

Major Premise: If the work program treats criminals and other citizens equally then it is fair.

Minor Premise: The work program treats criminals and other citizens equally.

First Conclusion: The work program is fair.

Second Argument

Major Premise: If an action or policy is fair it should be carried out.

Minor Premise: The work program is fair.

Conclusion: The work program should be carried out.

These two arguments can be combined, and the two-stage argument that results from their combination may be taken to represent the structure of the argument from fairness.

This analysis of the work program example suggests a scheme of the following sort. We call this scheme version 2 of the argument from fairness

Premise 1: If $\varphi$ treats $\alpha$ and $\beta$ equally, then $\varphi$ is fair. (Note 1)

Premise 2: $\varphi$ treats $\alpha$ and $\beta$ equally.

Interim Conclusion: $\varphi$ is fair.

Premise 3: If $\varphi$ is fair, then $\varphi$ should be carried out.

Ultimate Conclusion: $\varphi$ should be carried out.

Note that the structure of this argumentation scheme is that of a chained argument. First there is an interim conclusion, and then there is an ultimate conclusion based on this interim conclusion. There are other instances where an argumentation scheme is a composite made up of simpler schemes. As an example we might consider the argumentation scheme for the circumstantial ad hominem argument. This scheme incorporates the simpler scheme for argument from inconsistent commitments.

Next we have to examine a problem concerning the first version of the scheme for argument from fairness that also affects the second version as well. This problem concerns the major premise. This premise doesn't seem to be right, because there appear to be counterexamples to it as a generalization. We could use this scheme to support the following argument.

Criminals and other citizens ought to be treated equally.

Criminals ought to be locked up in prisons.

Therefore other citizens should also be locked up in prisons.

What this counterexample brings out is that the two groups being compared do not have equal status. One group has a status that could be called preferred, while the other group has a status that could be called non-preferred. The group made up of "other citizens" has a preferred status, whereas in contrast, the group made up of criminals has a 
non-preferred status. For this reason, the argument only works, or at least works best, if it goes one way. If we are arguing that criminals are to be treated like other citizens, the argument seems positive. However, if we are arguing that other citizens ought to be treated like criminals, the argument seems negative. What we see here then is that the argument from fairness works best when it argues for giving some group with less preferred status privileges enjoyed by a comparable group that has a more preferred status. We don't want to be equal to people who are in less preferred circumstances than ourselves. Generally we want to be equal to people who are at least perceived to be in more preferred circumstances than ourselves.

One way to deal with this problem is to bring the first critical question into play: are agents $\alpha$ and $\beta$ of the same kind? Are criminals and other citizens of the same kind? This question is hard to answer straightforwardly. Both criminals and other citizens are human agents. Both are citizens. In many respects they are the same kind. However, in some respects they are not the same kind. Presumably, criminals are not equal to other citizens who have not been convicted of a serious crime, because these other citizens have rights that criminals lack. So answering this critical question can be a bit tricky. But this example brings out the importance of this critical question. One proposal would be to emphasize its importance by removing this critical question and inserting it as a premise in the argument from fairness. This way of proceeding may generally be reasonable in some instances. It has been shown in the literature on argumentation and artificial intelligence that critical questions can be represented as additional premises of an argumentation scheme. This procedure is explained in (Gordon, 2010).

These remarks suggest a scheme of the following sort, which we will call version 3 of the argumentation scheme for argument from fairness.

Premise 1: Agents $\alpha$ and $\beta$ are of the same kind.

Premise 2: $\varphi$ treats $\alpha$ and $\beta$ equally.

Premise 3: If $\varphi$ treats $\alpha$ and $\beta$ equally, then $\varphi$ is fair.

Interim Conclusion: $\varphi$ is fair.

Premise 4: If $\varphi$ is fair, then $\varphi$ should be carried out.

Ultimate Conclusion: $\varphi$ should be carried out.

Version 3 of the scheme eliminates the need for the first critical question, leaving only the four remaining critical questions matching the scheme. Premise 1 brings the tricky question of whether the two agents are the same kind into the foreground, instead of leaving it in the background as a critical question. This might make the argumentation scheme for argument from fairness easier to apply, because it needs to be considered right away when analyzing an argument. It may be, however, that other examples will show that this premise has still been formulated in a way that is not adequate to deal with the kinds of problems suggested by this example. It may be that the two agents need to be of the same kind in some particular respect that needs to be specified in order to make the scheme work.

\section{Second Example of Argument from Fairness}

This example appeared in the Globe and Mail on 16/09/2011 with the title 'PCs Slam Liberals over Ontario Energy Ads'. In the ad, a party release of the Progressive Conservative party attacked what the Conservatives take to be taxpayer-funded ads that supported the Liberal campaign and were paid for by the Ontario Sustainable Energy Association. It was alleged that the OSEA had received millions of dollars in provincial funding, and had spent $\$ 200,000$ of that money on television ads praising the province's funding for the green energy sector. The text of the argument is quoted below. It could be called the unfair funding argument.

The PC party issued a release Friday morning slamming the ads, saying: "While Ontario families are struggling to make ends meet because of Dalton McGuinty's tax grabs and skyrocketing hydro bills, today Ontario families learned they are also footing the bill for Dalton McGuinty to funnel millions to an organization-the Ontario Sustainable Energy Association-that is running ads in support of the Liberal's re-election campaign."

This argument is a complex network of argumentation to disentangle. It seems to involve two separate arguments. One is based on the allegation that a political party is using government funds collected from taxpayers to support an organization that is running ads in support of the government party's re-election campaign. This kind of activity may be illegal. Certainly it is unethical. The other argument is basically an argument from fairness. This argument states two basic claims. One is that Ontario families are struggling to make ends meet because of high taxes imposed by the government. The other is that the government is spending millions of dollars to support an organization that is running ads in support of their re-election campaign. These two allegations, when put together, 
make up strong support for the conclusion that the government is acting in a way that is unfair to the Ontario families. One problem posed by this example is that of trying to disentangle these two arguments. The other problem is to try to isolate the argument from unfairness to see how it might be fitted to the scheme for argument from unfairness.

The best place to begin is to make up a key list representing the most significant propositions in the sequence of argumentation in the example. These might be listed as follows.

Ontario families are struggling to make ends meet.

Ontario families have to pay high taxes and hydro bills imposed by the provincial government.

Ontario families pay the tax bill to fund millions that go to support the OSEA.

The provincial government used public money to support OSEA.

Ontario families are struggling to make ends meet.

It is unfair that private organizations use money received from the government to support a political party [implicit premise].

OSEA is a private organization.

OSEA ran ads supporting the Liberal campaign.

OSEA should not sponsor ads supporting the Liberals.

The next part of the problem is to separate out the part of this complex sequence of argumentation that is based on argument from unfairness. The first step in this process is to identify the scheme for argument from unfairness that needs to be used. Here we will do this by making a version of the scheme for argument from unfairness that corresponds to the third version of the scheme for argument from fairness identified above. From this point onwards, we will use the following negative variant of version 3 of the scheme for argument from fairness. We call this scheme the negative variant of version 3 of argument from fairness.

Premise 1: Agents $\alpha$ and $\beta$ are of the same kind.

Premise 2: $\varphi$ treats $\alpha$ and $\beta$ unequally.

Premise 3: If $\varphi$ treats $\alpha$ and $\beta$ unequally, then $\varphi$ can be called unfair.

Interim Conclusion: $\varphi$ can be called unfair.

Premise 4: If $\varphi$ is unfair, then $\varphi$ should not be carried out.

Ultimate Conclusion: $\varphi$ should not be carried out.

The application of this scheme to the case in point is displayed in figure 4 . The premise in the bottom text box is an implicit premise that has been added in.

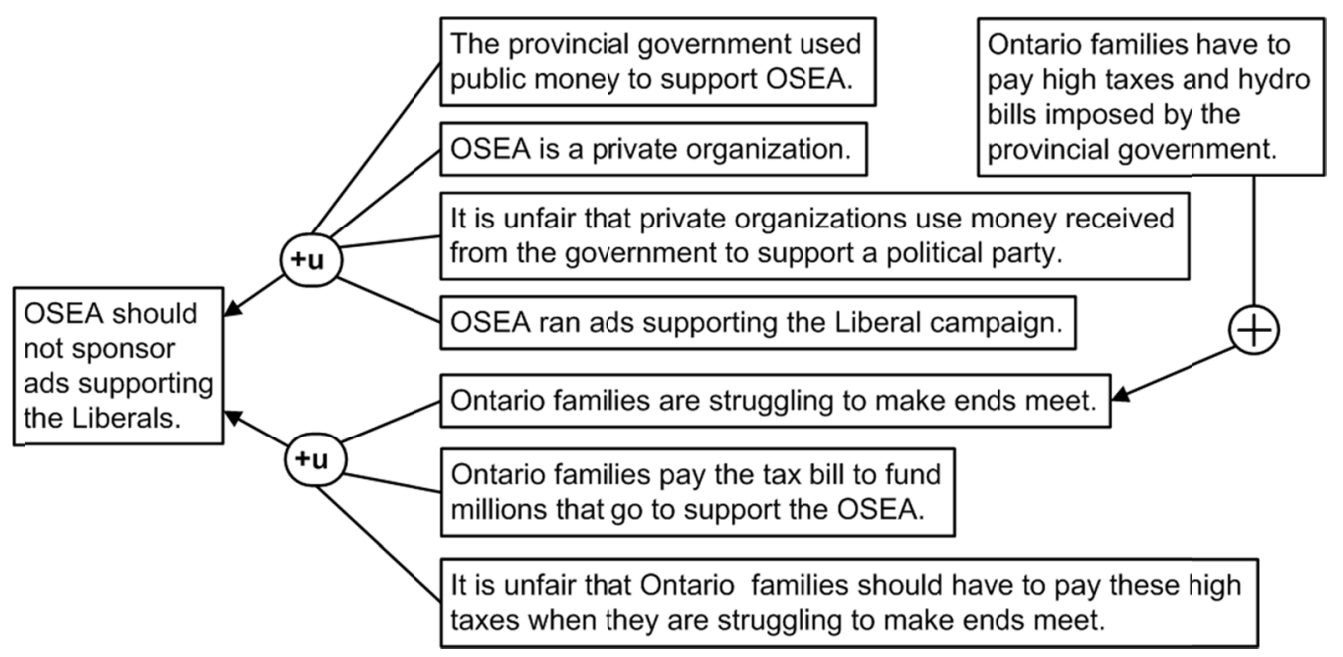

Figure 4. Argument diagram for the unfair funding example

So we see that, as shown in figure 4, there are two instances of argument from unfairness in this example. 


\section{Argument from Misplaced Priorities}

This example appeared in the Globe and Mail on 13/09/2011 with the title 'Tim Hudak Pledges to drain Ontario's Red Tape Swamp'. In the example, NDP (New Democratic Party) leader, Andrea Horwath, accused the other two parties, the Liberals and Conservatives, of practicing "groundhog politics" in which those parties' leaders "pop up once a day and hurl insults at each other instead of focusing on issues such as youth employment". At a training center funded by the Liberal government, she said, "You shouldn't have to wait until you are in your 30s for your first full-time job". The argument could be analyzed as the following set of premises and conclusion.

The other two party leaders hurl insults at each other instead of focusing on important issues such as youth unemployment.

Youth unemployment should be a more important priority than hurling insults at the other party leader.

This behavior shows misplaced priorities.

Therefore the groundhog politics of the two party leaders should be rejected.

This argument could be analyzed in other ways, by going into more depth of analysis. For example, Howarth also appears to be arguing that her party is focused on more important issues, and that therefore the leader of her party is more suitable to be elected than the leaders of the other two parties. This situation is similar to the argument shown in figure 3 , where the ultimate conclusion, shown at the left of the argument diagram, states that this action is unfair to Ontario families. But it does not show the ultimate conclusion of the argument, which can be viewed as an implicit statement saying that you, the person to whom the argument was directed, should not vote for the party who is responsible for this unfair action. There is always a choice when analyzing an argument how deeply one should go in inserting implicit premises or conclusions.

The situation is the same in this example. It is a simple example of argument from misplaced priorities, and is therefore a good example to use to illustrate this type of argument. But it could be analyzed more deeply by putting in a final implicit ultimate conclusion stating that the rejected argument from misplaced priorities is a reason why the person to whom the argument was directed should not vote for either of these parties. Instead, the message is that the person to whom the argument was directed should vote for the NDP.

The argumentation scheme for the argument from misplaced priorities can be expressed in the following general structure.

Premise 1: There is some prior argument or position $\pi$ that shows evidence of a priority ranking $P_{2}>P_{1}$.

Premise 2: The ordering of the priorities should be that $\mathrm{P}_{1}>\mathrm{P}_{2}$.

Interim Conclusion: $\pi$ shows misplaced priorities.

Ultimate Conclusion: Therefore $\pi$ should be rejected.

Note that the structure of this argumentation scheme is that of a chained argument. First there is an interim conclusion, and then there is an ultimate conclusion based on this interim conclusion. The interim conclusion could be omitted, arguably, since the second and third premises already demonstrate that the priorities are misplaced. Adding the interim conclusion merely makes the rationale of the argument more explicit. It can be put in or not as the user wishes.

In order for an argument used in a given case to qualify as fitting the scheme for argument from misplaced priority, it has to meet several requirements. One is that the argument has to be opposed to a prior argument or position put forward by one party in a discussion. Another is that this prior argument or position has to show evidence of a priority ordering. In the simplest, and it appears the most typical case, there are only two priorities, but it is possible that in some examples yet to be found there can be more than two involved. Another is that the argument or position has to be held to be based on a comparative weighing of these priorities. Another is that the argument makes the claim that the priorities in the prior argument are misplaced. That is, the responding argument claims that the prior argument has got the priorities the wrong way around.

The scheme for argument from misplaced priorities is a form of criticism of an opponent's argument based on the premises that the opponent's actions suggest a commitment to one proposition on the basis of a priority to it over another proposition. The argument is that this balancing of commitments is based on a misplaced priority, meaning that the opponent has a priority backwards compared to how it should really be placed. Basically it says that this party has his priorities wrong, therefore you should reject his argument (position).

This example appeared in the Toronto Star on 14/09/2011 with the title 'Hudak Still Intends to Make Sex Offender Registry Public'. In the example, the Progressive Conservative leader, Tim Hudak, reaffirmed his plan to make the 
provincial sex offender registry public if he won the election. Even though the Ontario police went on record as being against this idea, Hudak said he would make the registry public so that parents can know where sex offenders are living in their communities and can take responsible action to protect themselves and their children. He put his argument in the form of a rhetorical question: "our right to security for kids, should it come ahead of the right to privacy for child predators?" This argument balances one right against another, and puts a priority on one. By this means, anyone who is opposed to the candidate's view is being put in a position of having allegedly placed his opposition on misplaced priorities.

A key list of the propositions used as premises in the argument, and that contains the ultimate conclusion at the bottom, can be drawn up as follows. In addition to the explicitly stated premise of the argument, it will be useful for us two insert two implicit premises that are relatively uncontroversial. An enthymeme, in current usage, is an argument that has one or more premises, or possibly a conclusion, not explicitly stated in the text, but that needs to have these propositions explicitly stated, to extract the complete argument from the text. Sometimes enthymemes are described as arguments with missing premises, but they can also have missing conclusions that need to be filled in before the structure of the argument can be properly understood and analyzed (Walton \& Macagno, 2009). In the key list below, two implicit premises have been inserted.

Key List for the Child Predators Example

If parents can know where sex offenders are living in their community, they can take responsible action to protect themselves and their children.

Implicit premise: A public sex offender registry would enable them to know where sex offenders are living in their community

This argument has put the right of privacy for child predators ahead of the right to security for children.

Implicit Premise: Making the sex offender registry public would violate the privacy of child predators.

Implicit Premise: Violating the rights of privacy of child predators would be unfair to the child predators.

Putting the right of privacy for child predators ahead of the right to security for children is a misplaced priority.

Therefore the sex offender registry should be made public.

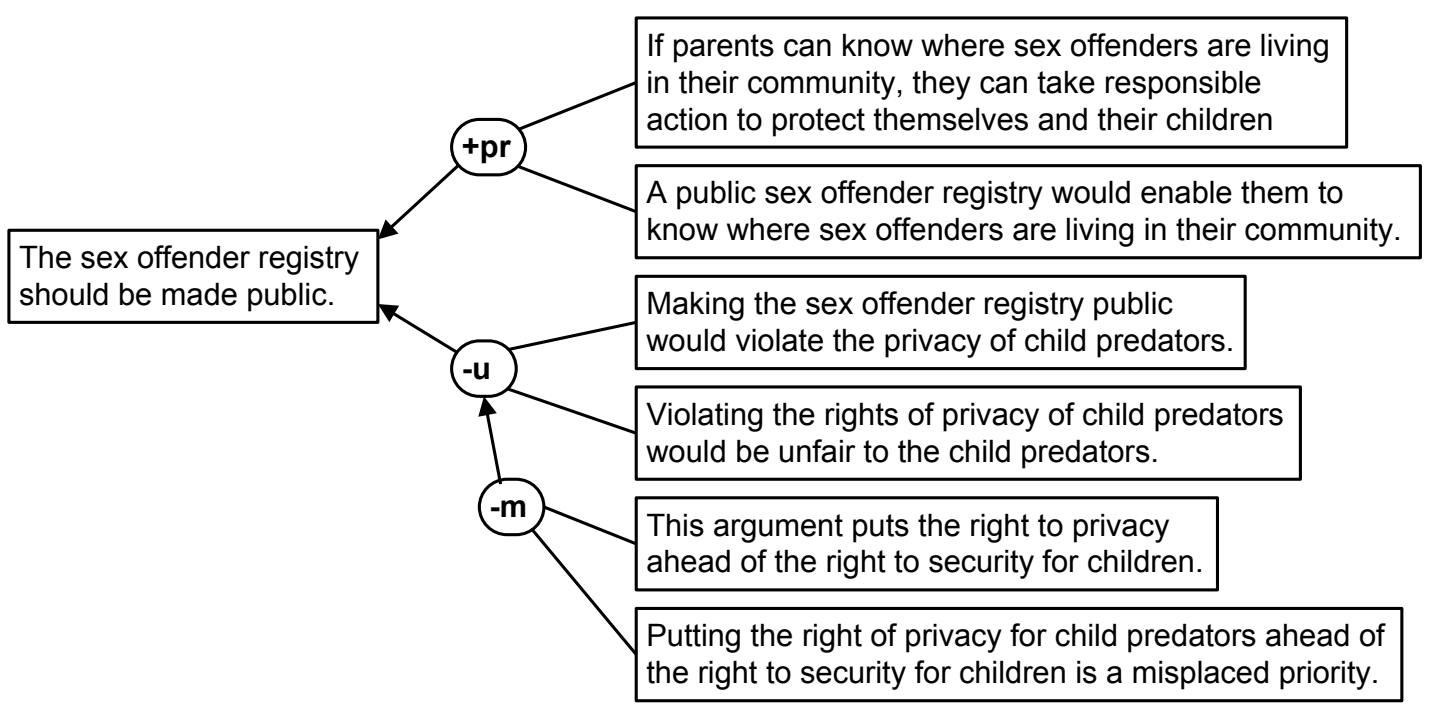

Figure 5. Diagram of the child predator argument

The argument can be visualized as shown in figure 5, where the node containing the notation pr represents the argumentation scheme for practical reasoning. According to this way of analyzing the example, the ultimate conclusion, the statement that the sex offender registry should be made public, appears at the far left of the diagram. At the top we have a pro argument supporting this conclusion. The pro argument is based on two 
premises. One states that a public sex offender registry would enable parents to know where sex offenders are living in their community. The other states that this knowledge would enable parents to take responsible action to protect themselves and their children. These two premises are combined using the argumentation scheme for value-based practical reasoning. According to this scheme, if an agent has a worthy goal in mind, and there is the means available that he can use to carry out the goal, then he should act in accord with this means. As noted above, this argument is a species of value-based practical reasoning (Walton, Reed \& Macagno, 2008, 324). It assumes that taking responsible action to protect yourself and your children is something worthy.

Below this first argument there is a second argument. It is a contra argument that presents an argument against the ultimate conclusion that the sex offender registry should be made public. It is based on an argument from rights that can be analyzed as an argument from fairness if you interpret it as arguing that violating the privacy of child predators would be unfair to the child predators, as indicated by that implicit premise in the key list. Finally, there is a third argument that is also a contra argument. It is shown in figure 5 as the bottom argument. It attacks the contra argument shown above it. By attacking the contra argument just above it, this contra argument supports the ultimate conclusion that the sex offender registry should be made public. However, it does this in an indirect way which requires some explanation.

In this case, as shown by the nesting of the two contra arguments, we have a refutation of a refutation. The bottom argument undercuts the top one in the meaning of (Pollock, 1995). Pollock drew a distinction between two kinds of counter-arguments called rebutters and undercutters. A rebutter gives a reason for denying a claim by arguing that the claim is a false previously held belief (Pollock, 1995, p. 40). An undercutter attacks the inferential link between the claim and the reason supporting it by weakening or removing the reason that supported the claim. In figure 4, argument from misplaced priorities is shown as an undercutter.

What is especially interesting about the way this argument is diagrammed is that it shows a feature called entanglement. In standard argument diagrams the arrows only go from text boxes to nodes that go to other text boxes. In other words, they only go from premises to conclusions. In figure 5, we have an argument diagrammed where there is an arrow leading from one node to another. This configuration represents the idea that one argument can attack another argument. Alternatively, one argument can support another argument. In either of these kinds of cases, the relationship between the two arguments is called entanglement (Verheij, 2003), where there is an arrow going from one node to another. This example is an interesting case where it is useful to employ an argument diagram that can use entanglement to show one argument attacking another.

\section{Example of a Borderline Argument}

Another example worthy of extended discussion is the following one, where Andrea Horwath, the leader of the NDP party criticized the government's plan to invest more money in entertainment tax deductions. This example appeared in the Toronto Star on 12/09/2011 under the title 'Horwath Vows to Cancel Corporate Entertainment Write-offs'.

"I hear every day people talking about how hard it is to make ends meet while at the same time the government hands out multimillion dollar tax breaks to banks and insurance companies", she said at a news conference at the Rogers Centre corporate box.

This case can be analyzed as an instance of argument from fairness (represented by f).

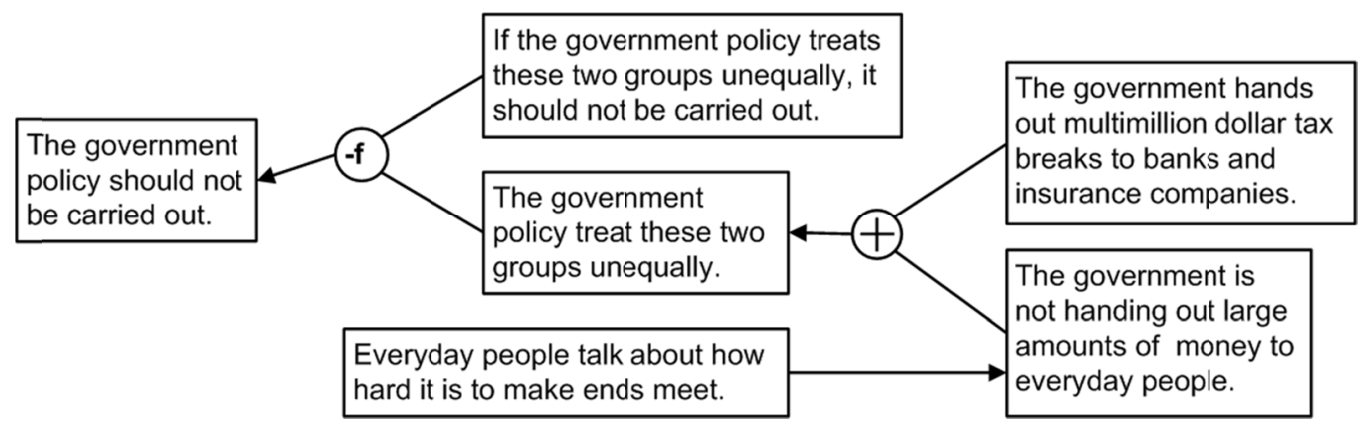

Figure 6. The tax breaks example as an instance of argument from fairness

The argument contrasts the case of people who are finding it hard to make ends meet with the case of the government handing out multimillion dollar tax breaks to banks and insurance companies. This contrast strongly 
suggests the injustice shown by this disparity. It's not fair, it is being suggested, that the government hands out lots of money to groups that already have lots of money, and at the same time fails to give money to those who are finding it hard to make ends meet. This way of analyzing the argument is shown in figure 6 , where the place of the scheme for argument from fairness (version 1) as applying to a particular argument is displayed.

But the interesting thing about this argument is that it can also be analyzed as an instance of the scheme for argument from misplaced priorities. Along these lines, the argument can be analyzed as having the following premises and conclusions. In figure 7 , the $\mathrm{m}$ in the node represents the scheme for argument from misplaced priorities.

Premise: Every day people say how hard it is to make ends meet.

Premise: The government hands out multimillion dollar tax breaks to banks and insurance companies.

Implicit Premise: The government's policy shows two different priorities.

Implicit Premise: The ordering of the priorities should be that helping people to make ends meet should be prior to handing out multimillion dollar tax breaks to banks and insurance companies.

Implicit Premise: In the government's policy, handing out multimillion dollar in tax breaks to Banks and insurance companies is prior to helping people to make ends meet.

[Interim Conclusion]: the government's actions show misplaced priorities.

Conclusion: the government's policy should be rejected.

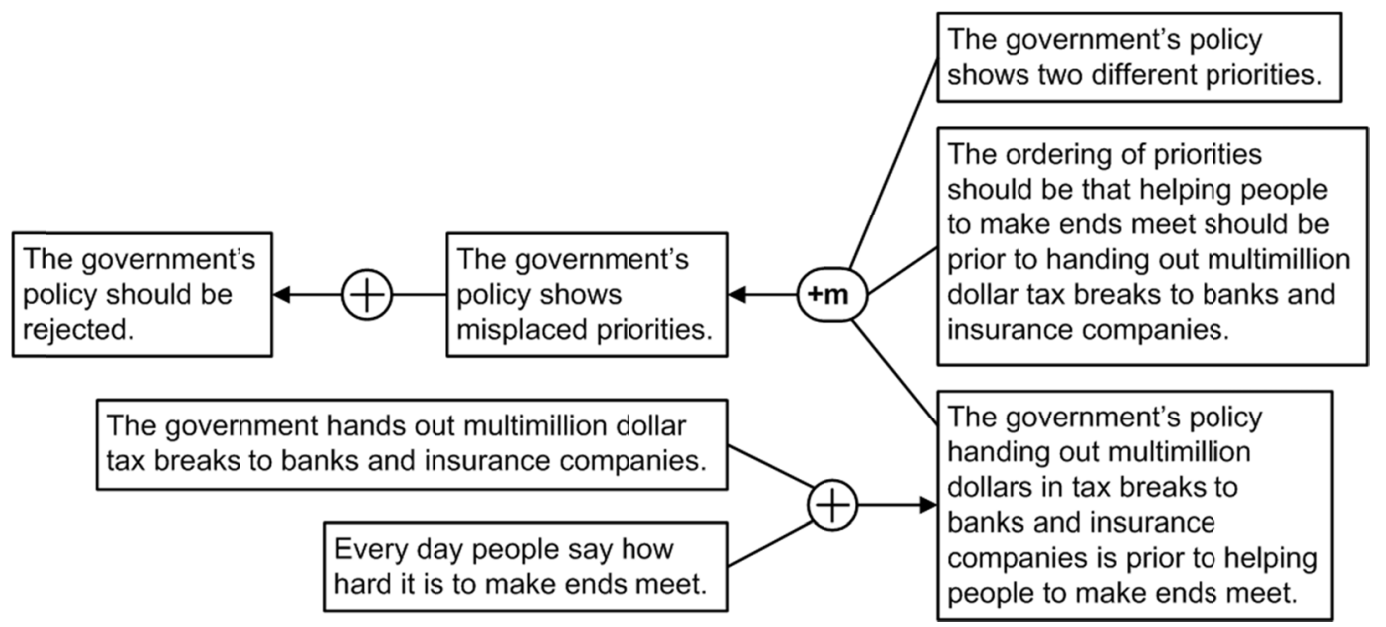

Figure 7. The tax breaks argument as an instance of misplaced priorities

There is also the premise stating that every day people say how hard it is to make ends meet. This premise supports the interim conclusion that the order of priorities is reversed in the government plan. The structure of this way of analyzing the argument is summarized in figure 6. How the scheme for argument from misplaced priorities fits a particular part of the argumentation in the tax breaks example is also shown in figure 7. Precisely how the argumentation scheme for argument from misplaced priorities, fits the argument in the case can be structured more abstractly as follows

First premise: there should be a balancing of priorities 'helping people make ends meet' $\left(\mathrm{P}_{1}\right)$ and providing tax breaks to help banks and corporations' $\left(\mathrm{P}_{2}\right)$ so that $\mathrm{P}_{1}$ has priority over $\mathrm{P}_{2}$.

Second premise: the government's actions show that it is giving priority to $\mathrm{P}_{2}$ over $\mathrm{P}_{1}$, reversing the proper order of priorities.

Interim Conclusion: the opponent has misplaced priorities.

Conclusion: the opponent's position should be rejected.

The ultimate conclusion is shown at the left of the diagram. The argument shown at the bottom of figure 7 represents the evidence put forward by Horwath to support the premise that the proper order of priorities has been reversed. 
In studying how schemes fit argumentation found in a real text discourse in some communication event like a newspaper editorial, there are basically three reasons why more than one scheme will fairly often fit a given argument. The first is that a given argument found in a text of discourse can be analyzed at different levels of depth, depending on how many implicit premises and conclusions are added in. The second reason is that there can be nesting of a subtype of argument into a more general type of argument. An example of this sort commonly found in analyzing political discourse of the kind found in elections is the borderline between instances of argument from inconsistent commitments and the circumstantial ad hominem argument. The circumstantial ad hominem argument takes this form: 'my opponent has shown by his arguments and actions that his commitments are inconsistent; therefore he does not have a trustworthy character (for example it might be alleged that he is a hypocrite); therefore his argument should be rejected'. The argument from inconsistent commitments merely points to an inconsistency in the opponent's commitments, but does not go so far as to attack the opponent's character based on this claim of inconsistency. What we have here is an instance where one type of argument, represented by an argumentation scheme, is nested within another more complex type of argument which also has an argumentation scheme. This kind of case often proves to be a difficulty when it comes to identifying the argumentation scheme in a given case. The reason is that the character attack part of the argument is often implicit, based on implicature and innuendo. Therefore it may be a matter of interpretation whether the argument should best be classified as a circumstantial ad hominem argument or only as an instance of argument from inconsistent commitments.

The third reason why more than one scheme can fit the same argument is simply the existence of vagueness, ambiguity, and other features of natural language discourse that very often necessitate postulating more than one interpretation of a given argument. Indeed, it is a common strategy in political argumentation to try to exploit vagueness and ambiguity legal way open for plausible deniability at some future time.

\section{Conclusions}

There is a reason why these two particular schemes, the argument from fairness and the argument from misplaced priorities, appear to both apply in some instances. Arguments from fairness are often based on premises about rights and values, and these types of cases tend to be ones involving priorities, for example priorities of values. Hence these two schemes are closely connected, and it is not too surprising that both of them could be involved in a single case. Still, we can ask whether one fits the tax breaks case better than the other.

In the tax breaks example, the argument from fairness leaps off the page as soon as one reads this text discourse and one is aware that there is an argumentation scheme for argument from fairness. Nevertheless, as shown above, applying the scheme for the argument from misplaced priorities does not really do a bad job of giving a helpful analysis of the argumentation in the case as well, and there seemed to be no decisive grounds for ruling it out. We leave it as an open question whether the one analysis is arguably better than the other one.

We propose that these two schemes ought to be added to the list in (Walton, Reed and Macagno, 2008, chapter 9), but there remains the question of whether the taxonomy used by Walton, Reed and Macagno contains related argumentation schemes that can be applied to satisfactorily capture the examples. Fairness is a value, so it could be argued that the existing scheme for argument from values already does the job of dealing with this group of examples. Another suggestion is that there might be a rule to the effect that we should be fair, so it could be argued that argument from fairness is a species of argument from a rule to a case. A third suggestion is that the examples of argument from fairness might be seen as resting on a definition of the term "fairness". On this basis it might be argued that argument from definition to verbal classification is sufficient to do the job.

We don't think that the third suggestion works, for the reason that all of the key terms in all of the argumentation schemes need to be defined, or at least clearly articulated for the users, and therefore any of these schemes could equally well be taken to represent argument from definition to verbal classification. We don't think that the second suggestion works for the reason that simply making a general rule to the effect that we should be fair does not provide sufficient guidance to judge what course of action is fair or not fair in a particular case in as explicit and helpful a way as using the scheme for argument from fairness.

We have put forward argumentation schemes representing argument from fairness and argument from misplaced priorities and have defended the claim that these two schemes fairly represent the arguments that we found in our data and analyzed in this paper. As well as presenting the two schemes, we have set requirements for identifying each of these types of arguments based on data in a given text discourse that can be helpful to aid users in the task of determining whether the argument they are confronted with fits one of these schemes.

The point has been made that argument from fairness, or argument from justice as it should be called in law, is an important subject for further study in the field of legal reasoning. Of course this point was fully realized and 
advocated by Perelman (1982). But now we are in a better position to more usefully apply the scheme to legal cases. As an example, we considered Popov v Hayashi (Popov v. Hayashi 2002 WL 31833731 (Cal. Superior, Dec. $18,2002)$ ), a case that has become a benchmark in artificial intelligence and law. (Note 2) (Wyner, Bench-Capon and Atkinson, 2007), the issue concerned which fan had ownership rights to a home run baseball hit into the stands by Barry Bonds. As shown in our analysis, although there were arguments on both sides on the issue of which party should be held to have possession of the ball, after examining all these arguments in much detail, Judge McCarthy in the end decided that any award to one party would be unfair to the other. He concluded on the basis of argument from fairness that each party had an equal and undivided interest in the ball, and ruled that its monetary value should be divided equally between them.

\section{Acknowledgements}

Work on this project was initially supported by a University of Windsor Internal SSHRC grant to Hans Hansen, and later by an Insight Grant to Douglas Walton from the Social Sciences and Humanities Research Council of Canada. We thank Richard Dumala of Information Technology Services, University of Windsor, for setting up the argument collection site. We are especially grateful to the four students who volunteered to work with us on this pilot study, Sam Atkin, Dillon Fowler, Laura Nicola, and Shane Perron. Their enthusiasm, insights and persistence, turned out to be of very valuable assistance to the project.

\section{References}

Aristotle. (1915). Ethica Nicomachea. In W. D. Ross (Ed), The Works of Aristotle Translated in English (Vol. IX). Oxford: Oxford University Press. Retrieved January 29, 2012, from http://classics.mit.edu/Aristotle/nicomachaen.5.v.html

Atkinson, K., \& Bench-Capon, T. (2007). Practical Reasoning as Presumptive Argumentation Using Action Based Alternating Transition Systems. Artificial Intelligence, 171(10-15), 855-874. http://dx.doi.org/10.1016/j.artint.2007.04.009

Bench-Capon, T. J. M. (2003). Persuasion in Practical Argument Using Value-based Argumentation Frameworks. Journal of Logic and Computation, 13(3), 429-448. http://dx.doi.org/10.1093/logcom/13.3.429

Bench-Capon, T. J. M., \& Prakken, H. (2010). Using Argument Schemes for Hypothetical Reasoning in Law. Artificial Intelligence and Law, 18, 153-174. http://dx.doi.org/10.1007/s10506-010-9094-8

Brosnan, S., \& de Waal, F. (2007). Monkeys Reject Equal Pay. Nature, (428), Dec. 3.

Gigerenzer, G. Todd, P. M., \& the ABC Research Group. (1999). Simple Heuristics That Make Us Smart. Oxford: Oxford University Press.

Gordon, T. F. (2010). The Carneades Argumentation Support System. In C. Reed, \& C. W. Tindale (Eds), Dialectics, Dialogue and Argumentation. London: College Publications.

Gosepath, S. (2011, Spring). Equality. In E. N. Zalta (Ed.), The Stanford Encyclopedia of Philosophy. Retrieved from http://plato.stanford.edu/archives/spr2011/entries/equality

Hansen, H. V., \& Walton, D. (2013). Argument Kinds and Argument Roles in the Ontario Provincial Election, 2011, Journal of Argumentation in Context, 2(2). http://dx.doi.org/10.1075/jaic.2.2.03han

Kienpointner, M. (1987). Towards a Typology of Argumentation Schemes. In F. H. van Eemeren et al., (Eds.), Argumentation: Across the Lines of Discipline (pp. 275-287). Dordrecht: Foris. http://dx.doi.org/10.1515/9783110867718.275

Mochales, R., \& Moens M. F. (2011). Argumentation Mining. Artificial Intelligence and Law, 19(1), 1-22. http://dx.doi.org/10.1007/s10506-010-9104-x

Mochales, R., \& Moens, M. F. (2009). Argumentation Mining: The Detection, Classification and Structure of Arguments in Text. Proceedings of the $12^{\text {th }}$ International Conference on Artificial Intelligence and Law. New York: Association for Computing Machinery, Inc., 98-107.

Perelman, C. (1980). Justice, Law and Argument. Dordrecht: Reidel. http://dx.doi.org/10.1007/978-94-009-9010-4

Perelman, C. (1982). The Realm of Rhetoric. Notre Dame: University of Notre Dame Press.

Perelman, C., \& Olbrects-Tyteca, L. (1969). The New Rhetoric. Notre Dame: University of Notre Dame Press.

Pollock, J. (1995). Cognitive Carpentry. Cambridge, Mass.: MIT Press.

Pollock, J. L., \& Cruz, J. (1999). Contemporary Theories of Knowledge. Totowa, N. Y.: Rowman and Littlefield. 
Prakken, H. (2011). An Overview of Formal Models of Argumentation and their Application in Philosophy. Studies in Logic, 4(1), 65-86.

Prakken, H., \& Sartor, G. (1997). Argument-based Logic Programming with Defeasible Priorities. Journal of Applied Non-classical Logics, 7, 25-75. http://dx.doi.org/10.1080/11663081.1997.10510900

Rahwan, I., \& Reed, C. (2009). The Argument Interchange Format. In I. Rahwan, \& G. Simari (Eds), Argumentation in Artificial Intelligence. Dordrecht: Springer. http://dx.doi.org/10.1007/978-0-387-98197-0_19

Rahwan, I., Banihashemi, B., Reed, C., Walton, D., \& Abdallah, S. (2011). Representing and Classifying Arguments on the Semantic Web. The Knowledge Engineering Review, 26(4), 487-511. http://dx.doi.org/10.1017/S0269888911000191

Verheij, B. (2003). Dialectical Argumentation with Argumentation Schemes: An Approach to Legal Logic. Artificial Intelligence and Law, 11, 167-195. http://dx.doi.org/10.1023/B:ARTI.0000046008.49443.36

Walton, D. (1998). Ad Hominem Arguments. Tuscaloosa: University of Alabama Press.

Walton, D. (2006). Fundamentals of Critical Argumentation. Cambridge: Cambridge University Press. http://dx.doi.org/10.1007/s10503-006-9013-z

Walton, D. (2010). Why Fallacies Appear to be Better Arguments Than They Are. Informal Logic, 30(2), 159-184.

Walton, D. (2011). Argument Mining by Applying Argumentation Schemes. Studies in Logic, 4(1), 38-64.

Walton, D., \& Macagno, F. (2009). Enthymemes, Argumentation Schemes and Topics. Logique et Analyse, 205, $39-56$.

Walton, D., \& Sartor, G. (2012). Teleological Justification of Argumentation Schemes. Argumentation.

Walton, D., Reed, C., \& Macagno, F. (2008). Argumentation Schemes. Cambridge: Cambridge University Press. http://dx.doi.org/10.1017/CBO9780511802034

Wyner, A., Bench-Capon, T. J. M., \& Atkinson, K. (2007). Argument, Values and Baseballs. In A. R. Lodder, \& L. Mommers (Eds.), Legal Knowledge and Information Systems (JURIX 2007) (pp. 151-162). Amsterdam: IOS Press.

\section{Notes}

Note 1. Saying that something is fair requires classifying that thing under the category of fairness. Hence a fuller exposition of the first premise should be 'If $\varphi$ treats $\alpha$ and $\beta$ equally, then $\varphi$ can be classified as fair' and the conclusion should be ' $\varphi$ can be classified as fair'. Finally, we need an implicit premise deriving from the scheme for argument form classification: if $\varphi$ is classified as fair, then $\varphi$ is fair. Here for the purpose of simplicity we restrict the discussion of this matter to a footnote.

Note 2. A whole issue of the journal Artificial Intelligence and Law (vol. 20, no. 1, 2012) is dedicated to the modeling of the case of Popov v. Hayashi using computational and formal argumentation tools.

\section{Copyrights}

Copyright for this article is retained by the author(s), with first publication rights granted to the journal.

This is an open-access article distributed under the terms and conditions of the Creative Commons Attribution license (http://creativecommons.org/licenses/by/3.0/). 